\title{
ANALISIS IMPLEMENTASI SEGMENTING, TARGETING DAN POSITIONING TERHADAP KEPUTUSAN PEMBELIAN PADA KEDAI ABG SIDOARJO
}

\author{
Satrio Sudarso \\ Jurusan Manajemen, Universitas Muhammadiyah Sidoarjo \\ satriosudarso@umsida.ac.id
}

\begin{abstract}
Discussion that became the background of this research is the development of the culinary business that is increasingly rapidly increasing so that business competition is increasing, so the right marketing strategy is needed. In order for culinary businesses to achieve the expected sales targets, companies must pay attention to strategies that influence purchasing decisions, including the right STP (segmentation, targeting, and positioning) strategy in order to win the competition in the market. This research is a quantitative research method with causality research techniques. The independent variables of this study are segmenting (X1), targeting (X2), positioning (X3) with the dependent variable is purchasing decisions $(Y)$. The population in this study are all consumers who make purchases at Kedai $A B G$. The sample used in this study were 50 respondents. The sampling technique used is non-probability sampling with incidental sampling method. The data collection instrument used was a questionnaire. The analysis technique used is multiple linear regression analysis and hypothesis testing using SPSS software for windows. The main results of this study are (1) segmentation has a positive effect and has a significant influence on purchasing decisions, (2) targeting has a positive effect and has a significant influence on purchasing decisions, (3) positioning has a negative effect and has no significant effect on purchasing decisions, (4) segmenting, targeting and positioning together (simultaneous/y) have a significant effect on purchasing decisions.
\end{abstract}

Keywords: segmenting; targeting; positioning; purchase decision.

$\triangle$ Corresponding author:

Email Address : satriosudarso@umsida.ac.id (Surabaya, Jawa Timur)

Received 7 Desember 2021, Accepted 5 Pebruari 2022, Published 23 Pebruari 2022

\section{PENDAHULUAN}

Salah satu kebutuhan primer setiap manusia adalah makanan dan minuman. Makanan memegang peranan penting bagi kelangsungan hidup manusia. Semakin berkembang ke arah masyarakat modern yang memiliki aktivitas yang berkunjung ke rumah makan merupakan pola saat ini yang cenderung bertatap muka, bersantai dan berbincang, sehingga cenderung mencari makanan, dan minuman di luar rumah berkonsep cepat saji dengan kualitas-kualitas tertentu yang memenuhi standar karena dinilai lebih efektif dan efisien. Wisata kuliner patut dikelola secara profesional dengan adanya usaha restoran/ rumah makan.

Di Kedai ABG ini termasuk ke dalam golongan restoran informal, karena di Kedai ABG ini industri pelayanan makanan dan minuman juga dikelola secara komersial dan profesional dengan lebih mengutamakan kecepatan pelayanan dan kepraktisan. Saat ini di Kota Sidoarjo produk olahan mie, hingga penyetan sudah menjamur di kalangan remaja dan anak muda. Terlihat dalam media sosial: instagram dan facebook banyak postingan anak muda yang memperlihatkan kebiasaan mereka yang nongkrong di warung makan, khususnya warung makan yang menyediakan produk berupa mie ayam, ayam penyet dan bebek penyet. Seiring semakin banyaknya perusahaan yang bersaing untuk memenuhi kebutuhan dan keinginan konsumen maka yang perlu diperhatikan adalah tentang bagaimana perusahaan mampu menciptakan segi unik pada produk maupun jasa yang ditawarkan. 
Banyaknya jumlah pembeli yang memiliki kebutuhan sangat beragam membuat perusahaan harus mengidentifikasi bagian pasar yang bisa dilayani dan dapat menguntungkan perusahaan. Perusahaan harus dapat merancang strategi pemasaran yang nantinya akan diarahkan untuk membangun hubungan yang benar dengan pelanggan yang tepat. Perusahaan harus menyusun strategi tentang segmenting, targeting, dan positioning (STP) yang diinginkan dengan tujuan untuk memenangkan persaingan bisnis yang terjadi.

Segmenting adalah aktivitas membuat pasar relatif lebih homogen yaitu dengan mengelompokkan pangsa pasar, sehingga kita bisa membeda bedakan secara spesifik antara satu dan yang lainya sebagaimana didefinisikan oleh Duncan "Grouping customer or prospects according to common characteristics, needs, wants and desire". Adapun keuntungan dari penggunaan segmentasi pasar dalam pemasaran antara lain dapat mendesain produk yang lebih responsif terhadap kebutuhan pasar, menganalisis pasar lebih mendalam, menemukan peluang, menguasai posisi yang kompetitif hingga menentukan strategi komunikasi yang efektif dan efisien.

Targeting atau menetapkan target pasar adalah tahap selanjutnya dari analisis segmentasi. Targeting adalah persoalan bagaimana memilih, menyeleksi dan menjangkau pasar. Bagaimana kita menyeleksi pasar sangat ditentukan oleh bagaimana kita melihat pasar itu sendiri, sebagaimana didefinisikan oleh Duncan targeting sebagai "analyzing, evaluating and prioritizing those market segments deemed most profitable to pursue" Oleh karena itu penting dipahami struktur struktur atau kelompok kelompok yang ada di pasar. Target pemasaran dikatakan sebagai suatu proses penyesuaian antara marketing mix yang lebih khusus dengan kebutuhan dari pasar yang spesifik agar produk tersebut dapat berhasil di pasaran.

Kelebihan dalam menerapkan targeting adalah dapat memungkinkan perusahaan mengetahui siapa yang dianalisis agar membantu dalam mengerti potensi dan konsumen yang sebenarnya, memungkinkan perubahan untuk menilai permintaan yang potensial untuk produknya, mengidentifikasi produk yang menjadi kompetitor pada pasar spesifik hingga memungkinkan perusahaan untuk menempatkan produknya di pasar berdasarkan perkiraan kebutuhan dan pilihan. Kotler (2009) mendefinisikan positioning sebagai tindakan merancang tawaran dan citra perusahaan sehingga menempati suatu posisi yang jelas (dapat dibedakan dalam persaingan) di dalam benak konsumen atau pelanggan sasaranya. Positioning bertujuan agar produk kita dilihat oleh konsumen dilihat sebagai suatu hal yang unik, berbeda dan menempati pikiran dan hati pelanggan. Dengan adanya positioning menyebabkan calon konsumen memiliki penilaian tertentu terhadap brand dan mengidentifikasikan dirinya dengan brand tersebut.

Positioning menyangkut bagaimana perusahaan membangun kepercayaan dan keyakinan pelanggan. Positioning merujuk pada produk, merek dan perusahaan yang harus diposisikan dengan jelas di benak pelanggan di mana tujuanya agar produk, merek dan perusahaan memiliki identitas yang jelas di benak pelanggan. Hal tersebut diwujudkan melalui janji atau komitmen yang pada praktiknya dapat berupa positioning statement-slogan, logo, jingle dan aneka atribut fisik lainya. Kotler dan Keller merumuskan keputusan pembelian adalah sebuah pendekatan penyelesaian masalah pada kegiatan manusia untuk membeli suatu barang atau jasa dalam rangka mencapai keputusan untuk memenuhi keinginan dan kebutuhanya.

Strategi pemasaran Segmenting, Targeting dan Positioning tersebut sebagai salah satu faktor utama yang dapat mempengaruhi keputusan pembelian. Sebelum memutuskan membeli suatu barang atau jasa, seorang konsumen akan melewati beberapa tahapan berpikir dalam keputusan pembelian. Konsumen akan membeli suatu barang atau jasa yang akan dinilai terdapat segi manfaat dan dapat memuaskan kebutuhan serta keinginan mereka. Adapun tahapan proses keputusan pembelian menurut Kotler dan Armstrong (2014) adalah sebagai berikut:

1. Pengenalan masalah

2. Pencarian informasi

3. Penilaian alternatif

4. Keputusan membeli

5. Perilaku setelah pembelian

Kedai ABG (Culinary 52) sendiri beralamatkan di Jalan Raden Patah No. 21 Daleman, Sidoarjo yang berdiri pada tanggal 
26 September 2021 oleh Oyot Kuwiakar, seorang seniman dan wirausahawan dalam bidang kuliner. Kedai ABG menyediakan menu mie ayam, nasi ayam dan nasi bebek spesial sambel bajak bumbu kaldu. Membuka kedai mie dan penyetan saat ini merupakan usaha yang menjanjikan disamping banyaknya usaha kedai mie dan nasi penyetan yang sekarang sudah sangat booming di kalangan masyarakat. Kedai ini sendiri sekarang menjadi sebuah alternatif sebagai makanan olahan siap saji yang harganya sangat terjangkau dan menjadi referensi masyarakat, khususnya kaum milenial.

Kedai ABG mempunyai segmentasi pasar yang agak berbeda dan beragam, dilihat dari konsep kedai yang semi resto dan semi café menjadikan kedai ini pantas dipakai untuk makan berat oleh masyarakat umum ataupun sekedar nongkrong khususnya oleh kawula muda. Semakin merebaknya pembukaan tempat makan di Sidoarjo, namun kedai $\mathrm{ABG}$ tetap bisa menjaga eksistensinya untuk menarik banyak konsumen yang datang berkunjung dan mengkonsumsi produk kulinernya. Hal tersebut didukung dengan penerapan segmenting, targeting dan positioning yang tepat. Akan tetapi penerapannya belum matang dan mencapai batas maksimal, sehingga membuat peneliti ingin mengetahui lebih lanjut tentang penerapan segmenting, targeting dan positioning yang saat ini tengah dijalankan oleh Kedai ABG dalam menjalankan dan mengembangkan operasional usahanya.

Penelitian sebelumnya dilakukan oleh Safitra H, Ravindra (2017) berjudul "Analisis Pengaruh Strategi Segmenting, Targeting dan Positioning Terhadap Keputusan Pelanggan Membeli Nu Green Tea" dengan persamaan pada variabel $\mathrm{X}$ dan variabel $\mathrm{Y}$ yang diteliti, akan tetapi memiliki titik perbedaan pada objek penelitian dan beberapa hasil temuan penelitian yang berbeda. Berdasarkan latar belakang masalah tersebut, maka peneliti membuat rumusan masalah sebagai berikut:

1. Bagaimana pengaruh implementasi keputusan pembelian ditinjau dari Segmenting pada Kedai ABG Sidoarjo?

2. Bagaimana pengaruh implementasi keputusan pembelian ditinjau dari Targeting pada Kedai ABG Sidoarjo?
3. Bagaimana pengaruh implementasi keputusan pembelian ditinjau dari Positioning pada Kedai ABG Sidoarjo?

4. Bagaimana pengaruh implementasi keputusan pembelian secara simultan ditinjau dari Segmenting, Targeting Dan Positioning pada Kedai ABG Sidoarjo?

Sesuai dengan latar belakang dan rumusan masalah di atas, maka tujuan penelitian ini adalah untuk mengetahui:

1) Pengaruh implementasi keputusan pembelian ditinjau dari Segmenting pada Kedai ABG Sidoarjo

2) Pengaruh implementasi keputusan pembelian ditinjau dari Targeting pada Kedai ABG Sidoarjo

3) Pengaruh implementasi keputusan pembelian ditinjau dari Positioning pada Kedai ABG Sidoarjo

4) Pengaruh implementasi keputusan pembelian secara simultan ditinjau dari Segmenting, Targeting Dan Positioning pada Kedai ABG Sidoarjo

\section{METODE PENELITIAN}

\section{Pendekatan Penelitian}

Variabel dalam penelitian ini terdiri dari dua macam yaitu variabel terikat dan variabel bebas. Dalam penelitian ini yang menjadi variabel terikat adalah keputusan pembelian (Y). Sedangkan yang menjadi variabel bebas dalam penelitian ini adalah segmenting (X1), targeting (X2) dan positioning (X3). Penelitian ini menggunakan metode kuantitatif. Penelitian kuantitatif dapat diartikan sebagai metode penelitian yang berlandaskan pada filsafat positivisme, digunakan untuk meneliti populasi atau sampel tertentu, teknik pengambilan sampel pada umumnya random, pengumpulan data menggunakan instrument penelitian, analisis data bersifat kuantitatif atau statistik untuk menguji hipotesis yang telah ditetapkan (Sugiyono, 2013).

\section{Populasi, Besaran Sampel, dan Teknik Sampling \\ Populasi yang digunakan} dalampenelitian ini adalah semua konsumen Kedai ABG Sidoarjo. Populasidalam penelitian ini bersifat infinite yang bersifat tidak terbatas, tidak terhingga atau jumlahnya tidak diketahui. Teknik pengambilan sampel 
yang digunakan dalam penelitian ini adalah non probability sampling berupa accidental sampling yaitu suatu metode penentuan sampel dengan mengambil responden yang kebetulan ada atau tersedia di suatu tempat. Dalam penentuan sampel peneliti berpedoman pada pendapat Roscoe dalam buku Sugiyono (2015) yang menyatakan penentuan ukuran sampel sebagai berikut "Bila dalam penelitian akan melakukan analisis dengan multivariate (misalnya korelasi atau regresi berganda), maka jumlah anggota sampel minimal 10 kali dari jumlah variabel yang diteliti".

Jumlah dari variabel dependen dan independen dalam penelitian ini adalah 4, maka anggota sampel yang digunakan berjumlah $10 \times 4=40$, di mana peneliti menambahkan jumlah sampel menjadi sebanyak 50 orang untuk lebih mendapatkan data yang lebih variatif guna lebih tepatnya pengukuran dan antisipasi data error.

\section{Teknik Pengumpulan Data}

Teknik pengumpulan data dalam penelitian ini menggunakan wawancara dan dokumentasi. Wawancara digunakan dengan menggunakan alat bantu yaitu kuesioner dan metode dokumentasi dilakukan untuk mendapatkan data-data sekunder. Instrumen kuesioner (angket) dalam bentuk checklist () yang sudah disediakan alternative jawabannya sehingga responden tinggal memilih jawaban yang tersedia. Skala pengukuran menggunakan skala likert.

Analisis data menggunakan analisis deskriptif dan analisis kuantitatif. Analisis deskriptif digunakan untuk mendeskripsikan atau memberi gambaran tentang deskrpsi segmenting, targeting dan positioning dan pengaruhnya terhadap keputusan pembelian, sedangkan analisis kuantitatif digunakan untuk meneliti sampel tertentu yang bersifat kuantitatif dan bertujuan untuk menguji hipotesis yang telah ditetapkan.

\section{Teknik Analisis}

Penelitian ini menggunakan analisis regresi linear berganda dan koefisien determinasi. Sebelum dilakukan analisis regresi linear berganda, dilakukan uji validitas dan uji reliabilitas. Koefisien determinasi digunakan untuk mengetahui presentase perubahan variabel terikat yang disebabkan oleh variabel bebas. Uji hipotesis menggunakan uji $\mathrm{t}$ dan uji $\mathrm{F}$. Uji $\mathrm{t}$ untuk mengetahui pengaruh segmenting, targeting dan positioning terhadap keputusan pembelian secara parsial, sedangkan uji $\mathrm{F}$ digunakan untuk mengetahui pengaruh segmenting, targeting dan positioning terhadap keputusan pembelian secara bersamaan (simultan).

\section{Definisi Operasional Variabel}

Definisi operasional variabel dalam penelitian ini adalah sebagai berikut:

1. Strategi segmenting (X1)

Indikator-indikator segmenting menurut Kotler dan Armstrong, terdiri dari:
a. Demografi
b. Geografi
c. Psikografi
d. Perilaku

2. Strategi targeting (X2)

Indikator-indikator targeting menurut Tjiptono), terdiri dari:

a. Konsentrasi segmen tunggal.

b. Spesialisasi selektif

c. Spesialisasi pasar

d. Spesialisasi produk

e. Pelayanan penuh

3. Strategi positioning (X3)

Indikator-indikator positioning menurut Tjiptonoterdiri dari:

a. Positioning berdasarkan atribut

b. Positioning berdasarkan harga dan kualitas

c. Positioning yang dilandasi dengan aspek penggunaan atau aplikasi Spesialisasi produk

d. Positioning berdasarkan pemakai produk

4. Keputusan Pembelian (Y)

Indikator-indikator keputusan pembelian menurut Kotler dan Keller terdiri dari:
a. Pengenalan masalah
b. Pencarian Informasi
c. Keputusan pembelian

\section{HASIL PENELITIAN}

\section{Deskripsi Kedai ABG Sidoarjo}

Kedai ABG Sidoarjo adalah sebuahkedai makanan lokal dengan cabang pertamanya di kota Sidoarjo. Berdiri sejak September 2021, Kedai ABG bertekad untuk menyajikan cita rasa menu makanan asli Indonesia. Dengan interior bergaya modis dan dilengkapi dengan fasilitas Wi-Fi yang cepat, 
Kedai ABG merupakan tempat berkumpul yang nyaman bersama teman, keluarga, atau pasangan. Segi pembeda dengan kedai lain terlihat dengan jelas rasa makanan yang disajikan sangat lezat dengan bumbu berasal asli Indonesia dan juga penyajian makanan berstandart resto atau Hotel berbintang.

Beraneka ragam pilihan minuman juga tersedia. Dengan pengalaman dalam bidang kuliner dari pemilik hingga bagian masak, Kedai ABG menawarkan pelanggan bukan hanya sekedar pengalaman menikmati makanan belaka tetapi juga sebagai 'MELTING POT' atau tempat berkumpulnya berbagai komunitas masyarakat yang mengharapkan pengalaman lebih dari sekedar kebutuhan makan, tetapi juga saling berjejaring sosial.

Tabel 1. Frekuensi Responden Berdasarkan Jenis Kelamin

\begin{tabular}{|c|l|c|c|}
\hline $\mathrm{N}_{0}$ & Jenis Kelamin & Frequency & Persen \\
\hline 1 & Laki-laki & 28 & $56,0 \%$ \\
2 & Perempuan & 22 & $44,0 \%$ \\
\hline & & Total 50 & $100,0 \%$ \\
\hline
\end{tabular}

Sumber: Data diolah, 2021

\section{Uji Validitas}

Tabel 2. Hasil Uji Validitas

\begin{tabular}{|c|c|c|c|c|}
\hline Variabel & $\begin{array}{l}\text { Item } \\
\text { Pertanyaan }\end{array}$ & \begin{tabular}{l|} 
Nilai Correlation \\
/ $\mathrm{r}$ Hitung
\end{tabular} & Sig. & Keterangan \\
\hline \multirow{7}{*}{$\begin{array}{l}\text { Segmentasi } \\
\left(\mathrm{X}_{1}\right)\end{array}$} & X1.1 & 0,537 & 0,000 & Valid \\
\hline & $\mathrm{X} 1.2$ & 0,632 & 0,000 & Valid \\
\hline & $\mathrm{X} 1.3$ & 0,394 & 0,000 & Valid \\
\hline & X1.4 & 0,526 & 0,000 & Valid \\
\hline & $\mathrm{X} 1.5$ & 0,460 & 0,000 & Valid \\
\hline & X1.6 & 0,485 & 0,000 & Valid \\
\hline & X1.7 & 0,639 & 0,000 & Valid \\
\hline \multirow{9}{*}{$\begin{array}{l}\text { Targeting } \\
\left(\mathrm{X}_{2}\right)\end{array}$} & $\mathrm{X} 2.1$ & 0,546 & 0,000 & Valid \\
\hline & $X 2.2$ & 0,384 & 0,000 & Valid \\
\hline & $\mathrm{X} 2.3$ & 0,512 & 0,000 & Valid \\
\hline & $\mathrm{X} 2.4$ & 0,367 & 0,000 & Valid \\
\hline & $\mathrm{X} 2.5$ & 0,528 & 0,000 & Valid \\
\hline & $\mathrm{X} 2.6$ & 0,390 & 0,000 & Valid \\
\hline & $\mathrm{X} 2.7$ & 0,499 & 0,000 & Valid \\
\hline & $\mathrm{X} 2.8$ & 0,536 & 0,000 & Valid \\
\hline & X2.9 & 0,448 & 0,000 & Valid \\
\hline \multirow{8}{*}{$\begin{array}{l}\text { Positioning } \\
\text { (X3) }\end{array}$} & X3.1 & 0,559 & 0,000 & Valid \\
\hline & X3.2 & 0,505 & 0,000 & Valid \\
\hline & X3.3 & 0,416 & 0,000 & Valid \\
\hline & X3.4 & 0,503 & 0,000 & Valid \\
\hline & $\mathrm{X} 3.5$ & 0,548 & 0,000 & Valid \\
\hline & X3.6 & 0,660 & 0,000 & Valid \\
\hline & X3.7 & 0,495 & 0,000 & Valid \\
\hline & X3.8 & 0,455 & 0,000 & Valid \\
\hline \multirow{6}{*}{$\begin{array}{c}\text { Keputusan } \\
\text { Pembelian }(\mathrm{Y})\end{array}$} & Y1 & 0,588 & 0,000 & Valid \\
\hline & $\mathrm{Y} 2$ & 0,516 & 0,000 & Valid \\
\hline & Y3 & 0,515 & 0,000 & Valid \\
\hline & Y4 & 0,758 & 0,000 & Valid \\
\hline & Y5 & 0,758 & 0,000 & Valid \\
\hline & Y6 & 0,613 & 0,000 & Valid \\
\hline
\end{tabular}

Sumber: Data diolah, 2021
Dilihat dari tabel tersebut, semua item pertanyaan dinyatakan valid karena semua item pertanyaan memiliki $r$ hitung yang lebih besar dari pada $r$ Tabel ( $r$ Hitung $>r$ Tabel) atau nilai dari sig dibawah dari 0,05 .

\section{Uji Reabilitas}

Tabel 3. Hasil Uji Reliabilitas

\begin{tabular}{|l|l|l|}
\hline Variabel & Cronbach's Alpha & Keterangan \\
\hline Segmentasi $\left(\mathrm{X}_{1}\right)$ & 0,631 & Reliabel \\
Targeting $\left(\mathrm{X}_{2}\right)$ & 0,616 & Reliabel \\
Positioning $\left(\mathrm{X}_{3}\right)$ & 0,612 & Reliabel \\
Keputusan Pembelian $(\mathrm{Y})$ & 0,685 & Reliabel \\
\hline
\end{tabular}

Sumber: Data diolah, 2021

Dilihat dari Tabel 3., hasil uji reliabilitas dalam penelitian ini menggunakan koefisien cronbach's alpha, dimana menurut Ghozali bahwa instrument dikatakan reliabel jika memiliki koefisien cronbach's alpha sama dengan 0.60 atau lebih.

\section{Analisis Regresi Berganda}

Tabel 4. Hasil Analisis Regresi Linier Berganda

\begin{tabular}{|c|c|c|c|c|c|}
\hline & Unstandartient & Coetficintsts & $\begin{array}{l}\text { standardined } \\
\text { Coefficints } \\
\text { Rata }\end{array}$ & & \\
\hline Mlodel] & B & Pu. Ifor & & 1 & Sig, \\
\hline $\begin{array}{l}\text { (Costaini) } \\
\text { Gompentsi }\end{array}$ & 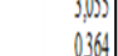 & $\begin{array}{l}2,19 \\
008\end{array}$ & 0305 & 1,111 & 0,269 \\
\hline Impgrting & 0,325 & 0,08 & 0,419 & 3971 & 000 \\
\hline Postioning & .01115 & 0,08 & 0,129 & $.1,1,1$ & 0193 \\
\hline
\end{tabular}

Sumber: Data diolah, 2021

Pembuktian dalam tabel tersebut dimaksudkan untuk menguji variasi suatu model regresi yang digunakan dalam menerangkan variabel bebas (X) terhadap variabel terikat $(\mathrm{Y})$ dengan cara menguji signifikansi dari koefisien regresinya. Hasil analisis regresi diperoleh nilai konstan sebesar 3,055 sedangkan nilai untuk variabel segmenting (X1) sebesar 0,364, variable targeting (X2) sebesar 0,325, variabel positioning (X3) sebesar (-0,115). Sehingga apabila dimasukkan dalam fungsi analisa regresi secara keseluruhan, maka diperoleh persamaan sebagai berikut.

$\mathrm{Y}=\mathrm{a}+\mathrm{b} 1 \mathrm{X} 1+\mathrm{b} 2 \mathrm{X} 2+\mathrm{b} 3 \mathrm{X} 3$

$\mathrm{Y}=3,005+0,364 \mathrm{X} 1+0,325 \mathrm{X} 2+$ $(-0,115) \mathrm{X} 3$ 
Melihat Tabel 4. di atas, berdasarkan hasil uji t (parsial) diperoleh nilai signifikansi segmenting 0,000. Karena nilai signifikansi lebih kecil dari 0,05 berarti $\mathrm{H} 0$ ditolak dan $\mathrm{H} 1$ diterima. Artinya, segmenting (X1) secara parsial berpengaruh signifikan terhadap keputusan pembelian (Y). Kesimpulannya adalah hipotesis yang berbunyi "Ada pengaruh antara segmenting terhadap keputusan pembelian Kedai ABG Sidoarjo terbukti kebenarannya.

Melihat Tabel 4. di atas, berdasarkan hasil uji t (parsial) diperoleh nilai signifikansi targeting 0,000. Karena nilai signifikansi lebih kecil dari 0,05 berarti $\mathrm{H} 0$ ditolak dan $\mathrm{H} 2$ diterima. Artinya, targeting (X2) secara parsial berpengaruh signifikan terhadap Keputusan pembelian (Y). Kesimpulannya adalah hipotesis yang berbunyi "Ada pengaruh antara targeting terhadap keputusan pembelian di Kedai ABG Sidoarjo terbukti kebenarannya.

Melihat Tabel 4. di atas Berdasarkan hasil uji t (parsial) diperoleh nilai signifikansi positioning adalah 0,193 . Karena nilai signifikansi lebih besar dari 0,05 berarti $\mathrm{H} 0$ diterima dan $\mathrm{H} 3$ ditolak. Artinya, positioning (X3) secara parsial tidak berpengaruh signifikan terhadap Keputusan pembelian (Y). Kesimpulannya adalah hipotesis yang berbunyi "Ada pengaruh antara positioning terhadap keputusan pembelian di Kedai ABG Sidoarjo tidak terbukti kebenarannya.

\section{Koefisien Determinasi $\left(\mathbf{R}^{2}\right)$}

Tabel 5. Hasil Uji Koefisien Determinasi

$$
\left(\mathbf{R}^{2}\right)
$$

\begin{tabular}{|c|c|c|c|c|}
\hline Model & $\mathbf{R}$ & R Square & $\begin{array}{l}\text { Adjusted R } \\
\text { Square }\end{array}$ & $\begin{array}{l}\text { Std. Error of the } \\
\text { Estimate }\end{array}$ \\
\hline 1! & & $0,65 !$ & 0,424 & 2,36265 \\
\hline
\end{tabular}

Sumber: Data diolah, 2021

Hasil olahan data pada Tabel 5, menunjukkan bahwa nilai koefisien korelasi (R) dan koefisien determinasi (R square). Dari Tabel di atas diketahui nilai $\mathrm{R}$ sebesar 0,651 menunjukkan bahwa pengaruh segmentasi, targeting, dan positioning terhadap keputusan pembelian produk Kedai ABG Sidoarjo, mempunyai pengaruh sebesar $65,1 \%$ atau memiliki hubungan yang kuat antara variable dependen dan independen. Dengan demikian menunjukkan bahwa keputusan pembelian dapat dijelaskan oleh segmenting, targeting dan positioning $65,1 \%$ dan sisanya sebesar $34,9 \%$ dijelaskan variabel lain yang tidak diteliti dalam penelitian ini.

\section{Uji Simultan (F)}

Tabel 6. Hasil Uji Simultan (F)

\begin{tabular}{|l|l|r|r|r|l|l|l|r|}
\hline Model & & $\begin{array}{l}\text { Sum of } \\
\text { Squares }\end{array}$ & Df & & $\begin{array}{l}\text { Mean } \\
\text { Square }\end{array}$ & $\begin{array}{l}\text { F } \\
\text { Hitung }\end{array}$ & Sig. & F Tabel \\
\hline 1 & Regresion & 394,867 & & 3 & 131,622 & 23,579 & 0,000 & 2,70 \\
& Residual & 535,883 & & 96 & 5,582 & & & \\
& Total & 930,750 & & 99 & & & & \\
\hline
\end{tabular}

Sumber: Data diolah, 2021

Pengaruh variabel segmentasi, targeting, dan positioning terhadap keputusan pembelian signifikan, ditunjukan oleh nilai sig sebesar 0,000 atau kurang dari 0,05 yang berarti $\mathrm{H} 0$ ditolak dan $\mathrm{H} 4$ diterima. Hasil dari pengujian secara simultan ini adalah segmenting, targetingdan positioning berpengaruh terhadap keputusan pembelian. Kesimpulannya adalah hipotesis yang berbunyi "Ada pengaruh antara segmenting,targeting dan positioning secara bersama - sama terhadap keputusan pembelian di Kedai ABG Sidoarjo" terbukti kebenarannya.

Uji Parsial (t)

Tabel 7. Hasil Uji Parsial (t)

\begin{tabular}{|c|c|c|c|c|c|c|c|}
\hline \multirow[b]{2}{*}{ Mode } & & \multicolumn{2}{|c|}{ Unstandardized Coefficients } & \multirow{2}{*}{$\begin{array}{l}\text { Standardized } \\
\text { Coefficients } \\
\text { Beta } \\
\end{array}$} & \multirow[b]{2}{*}{ thitung $S$} & & \multirow[b]{2}{*}{ t tabel } \\
\hline & & B & Std. Error & & & Sg, 1 & \\
\hline 1 & (Constant) & 3,055 & 2,749 & & 1,111 & 0,269 & \\
\hline & segmentassi & 0,364 & 0,088 & 0,395 & 4,132 & 0,000 & 1,600 \\
\hline & targeting & 0,325 & 0,082 & 0,419 & 3,971 & 0,000 & 1,600 \\
\hline & Positioning & $-0,115$ & 0,088 & $-0,129$ & $-1,311$ & 0,193 & \\
\hline
\end{tabular}

Sumber: Data diolah, 2021

Pengaruh dari masing-masing variabel segmentasi, targeting, dan positioning terhadap keputusan pelanggan Kedai ABG Sidoarjo, dapat dilihat dari arah tanda dan tingkat probabilitas. Jika tingkat sig <0,05, maka dapat dikatakan bahwa variabel tersebut berpengaruh signifikan adapun juga dengan membandingkan nilai $t$ hitung dengan $t$ Tabel jika t hitung > t Tabel maka variabel tersebut memiliki pengaruh signifikan terhadap variabel dependen. 


\section{PEMBAHASAN}

\section{Pengaruh Segmentasi Terhadap Keputusan Pembelian}

Berdasarkan hasil pengujian pada penelitian ini menyatakan bahwa segmentasi berpengaruh signifikan terhadap keputusan pembelian dan memiliki nilai yang positif. Hasil tersebut terlihat pada nilai signifikan sebesar 0,000 yang lebih kecil dari tingkat signifikan 0,05 atau nilai $t$ hitung yang lebih besar dari pada $t$ Tabel dan memiliki nilai $\mathrm{B}$ positif yaitu sebesar 0,364. Hal ini menjelaskan bahwa hasil penelitian ini menunjukan kondisi yang signifikan yang berarti semakin tinggi strategi segmentasi yang dijalankan maka tingkat keputusan pembelian semakin tinggi atau naik sebesar 0,364 atau sebesar $36,4 \%$.

Jika dilihat dari hasil kuesioner yang ada para responden lebih dominan setuju bahkan memilih sangat setuju dengan pernyataan yang ada, ini membuktikan bahwa responden yang termasuk dalam penelitian ini sudah sangat menyukai produk-produk yang ditawarkan oleh Kedai ABG walaupun ada juga beberapa responden yang memilih untuk netral dalam pelayanan yang ada namun persentase dari pendapat mereka sedikit. Hal ini sesuai dengan teori yang dikemukakan oleh Hasan (2013) yaitu "Proses membagi pasar untuk suatu produk ke dalam kelompok/komunitas yang lebih kecil dimana para anggota masing-masing kelompok mempunyai kesamaan persepsi, keinginan dan motivasi yang sama terhadap faktor-faktor yang mempengaruhi permintaan". Oleh karena itu segmenting menjadi salah satu pertimbangan penting bagi konsumen dalam melakukan proses keputusan pembelian.

Kedai ABG Sidoarjo terletak ditempat yang strategis, berada di pusat kota, dan menjadikannya tempat yang unik karena berada dilingkungan business center serta fasilitas pelayanan umum dimana para pengunjung dapat merasakan cita rasa masakan hotel berbintang sekaligus tempat yang nyaman. Kedai ABG yang terletak di Jl. Raden Patah Sidoarjo, berhasil melakukan segmenting atau pembagian segmen pasar dengan baik. Oleh sebab itu, perusahaan harus selalu memperbaharui sistem pemasaran yang mulai terkontrol dengan baik dan terus melakukan pengamatan terhadap segmen pasar konsumen yang semakin mengikuti perubahan tren.

\section{Pengaruh Targeting Terhadap Keputusan Pembelian}

Berdasarkan hasil pengujian pada penelitian ini menyatakan bahwa targeting berpengaruh positif dan signifikan terhadap keputusan pembelian. Hasil tersebut terlihat pada nilai signifikan yaitu 0,000 yang mana nilai ini lebih kecil dari tingkat signifikan 0,05 atau $t$ hitung lebih besar dari pada $t$ Tabel dan memiliki nilai B positif, yaitu sebesar 0,325. Hasil penelitian ini menunjukan kondisi yang signifikan dan positif yang berarti semakin baik persepsi pelanggan terhadap strategi targeting yang dijalankan, maka semakin tinggi tingkat keputusan pembelian atau sebaliknya semakin buruk persepsi pelanggan terhadap targeting maka semakin rendah keputusan pembelian. Jika dilihat dari hasil kuesioner yang ada para responden lebih dominan setuju bahkan memilih sangat setuju dengan pernyataan yang ada, ini membuktikan bahwa responden yang termasuk dalam penelitian ini sudah merasa puas dengan target yang telah ditentukan walaupun ada juga beberapa responden yang memilih untuk kurang setuju bahkan sangat tidak setuju dalam kriteria targeting yang ditentukan.

Targeting memang menjadi salah satu hal yang penting pada saat perusahaan ingin menetapkan penentuan target pasar yang akan dimasukinya, karena jika terjadi kesalahaan maka bisa berujung pada ketidaktertarikan akan produk tersebut. Namun, sebaliknya jika penetapan target pasar yang ditetapkan sangat sesuai maka akan terjadi efek loyalitas dalam benak konsumen dan hal itulah yang terjadi pada Kedai ABG yang menetapkan bahwa targeting untuk semua kalangan. Para pelanggan merasa cocok dan sesuai dengan keinginan mereka, sehingga menciptakan efek loyal bagi pelanggan dengan targeting yang telah ditetapkan perusahaan juga mengimbangi dengan fasilitas yang menunjang untuk mendapatkan nilai tambah dari para pelanggan.

Bagi para pesaing yang ada harus juga menjadi sorotan dari Kedai ABG karena dapat pula meskipun memiliki target yang sama, para pesaing mungkin saja menawarkan fasilitas atau bahkan program promo yang tidak ditawarkan oleh Kedai ABG dan bukan 
tidak mungkin pelanggan kedai $\mathrm{ABG}$ beralih kepada para pesaing.

Temuan ini sesuai dengan teori dari

Tjiptono dan Chandra (2012) yang mengemukakan pasar sasaran adalah proses mengevaluasi dan memilih satu atau beberapa segmen pasar yang dinilai paling menarik untuk dilayani dengan program pemasaran spesifik perusahaan" dan membuktikan bahwa semakin baik strategi targeting yang tepat maka akan semakin meningkatkan minat konsumen dalam melakukan keputusan pembelian. Keberhasilan segmenting atau tahap pembagian segmen pasar harus diikuti dengan tahap targeting atau penentuan pasar yang ingin dituju dengan benar. Target pasar dari pihak Kedai ABG adalah semua kalangan yang lebih terfokus pada anak muda. Dengan produk yang mulai variatif, maka dapat membuat ketertarikan tersendiri bagi para konsumen.

\section{Pengaruh Positioning Terhadap Keputusan Pembelian}

Berdasarkan hasil pengujian pada penelitian ini menyatakan tidak signifikan terhadap keputusan pembelian. Hasil tersebut terlihat pada nilai signifikansi, yaitu: 0,193 yang mana nilai ini lebih besar dari tingkat signifikan 0,05 atau t hitung lebih kecil dari pada $\mathrm{t}$ Tabel dan memiliki nilai $\mathrm{B}$ negatif yaitu sebesar -0.115 . Hasil ini menjelaskan bahwa hasil penelitian menunjukan kondisi yang tidak signifikan di mana positioning tidak berpengaruh terhadap keputusan pembelian.

Kedai ABG adalah brand lokal yang diharapkan mampu bersaing dengan brand nasional yang sudah terkenal didalam negeri. Sebagian pengunjung merasa bahwa porsi makanan dengan harga yang ditawarkan adalah cukup mahal. Alasan inilah yang membuat Kedai ABG mendapatkan respon yang kurang baik dari para pengunjung. Oleh sebab itu, pihak Kedai ABG harus membuat produk yang berbeda dan lebih inovatif. Misalnya dengan membuat produk yang unik dan menarik perhatian konsumen. Sehingga produk Kedai ABG dapat mendapatkan image yang baik di benak para konsumen.

$\begin{array}{lrr}\text { Pengaruh } & \text { Segmentasi, } & \text { Targeting, dan } \\ \text { Positioning } & \text { Terhadap } & \text { Keputusan } \\ \text { Pembelian } & & \end{array}$

Hasil pengujian yang dilakukan, segmentasi dan targeting berpengaruh secara simultan terhadap keputusan pembelian. Hasil tersebut terlihat pada nilai signifikan sebesar 0,000 yang lebih kecil dari batas taraf signifikan yaitu 0,05 atau dilihat dari nilai $F$ hitung dan $\mathrm{F}$ Tabel yang dimana $\mathrm{F}$ hitung harus lebih besar dari $\mathrm{F}$ tabel. Hasil tersebut menunjukan bahwa segmentasi dan targeting secara simultan berpengaruh terhadap keputusan pembelian. Variabel positioning tidak berpengaruh secara simultan terhadap keputusan pembelian, karena dari hasil yang terlihat nilai signifikan positioning sebesar $0,193>$ dari batas signifikan, yaitu: 0,05.

Hasil penelitian ini sesuai dengan penelitian yang dilakukan oleh Safitra (2017) yang menyatakan segmenting, targeting dan positioning berpengaruh signifikan terhadap keputusan pembelian. Produk yang beraneka macam varian, dapat dinikmati oleh semua kalangan, fasilitas pendukung yang tersedia di Kedai ABG khususnya di area pusat kota Sidoarjo dimana menjadi kekuatan yang dimiliki oleh perusahaan, karena bisa memilih semua segmen pasar. Dengan tidak adanya batasan kalangan konsumen, membuat Kedai ABG menjadi brand yang memiliki citra baik dimata konsumen. Hal ini, mendorong kosumen untuk menjadi loyal kepada perusahaan serta melakukan pembelian produk secara berkelanjutan.

Perbedaan dengan penelitian terdahulu yang dilakukan oleh Tumini dkk (2021) dengan judul "Pengaruh Strategi Segmenting, Targeting, Positioning terhadap keputusan pembelian (Studi pada Sepeda Motor Matic di Kota Probolinggo) menunjukkan bahwa Segmenting, Targeting, Positioning berpengaruh signifikan terhadap keputusan pembelian sepeda motor matic dengan hasil uji hipotesis secara simultan membuktikan bahwa ada pengaruh yang signifikan secara simultan terhadap keputusan pembelian sepeda motor matic di kota Probolinggo. Sedangkan persamaanya ada dua variabel yaitu segmentasi dan targeting yang berpengaruh secara simultan terhadap keputusan pembelian.

\section{KESIMPULAN DAN SARAN}

\section{Kesimpulan}

Berikut kesimpulan penelitian berdasarkan 
hasil yang diperoleh dari penelitian dan pembahasan sebagai berikut:

1) Variabel segmenting secara parsial berpengaruh positif dan signifikan terhadap keputusan pembelian pada Kedai ABG Sidoarjo

2) Variabel targeting secara parsial berpengaruh positif dan signifikan terhadap keputusan pembelian pada Kedai ABG Sidoarjo

3) Variabel positioning secara parsial berpengaruh negatif dan tidak signifikan terhadap keputusan pembelian pada Kedai ABG Sidoarjo.

4) Variabel segmenting, targeting dan positioning secara bersama-sama (simultan) berpengaruh signifikan terhadap keputusan pembelian pada Kedai ABG Sidoarjo

5) Variabel segmenting merupakan variabel dominan yang mempengaruhi keputusan pembelian di Kedai ABG Sidoarjo.

\section{Saran}

Semakin baik strategi segmenting yang diterapkan maka akan meningkatkan keputusan pembelian konsumen. Strategi segmenting dapat dilakukan dengan memilih sasaran yang tepat agar konsumen semakin tertarik dan terus memilih produk-produk dari Kedai ABG Sidoarjo, dengan memperhatikan kriteria keberhasilan segmentasi yaitu keanekaragaman, dapat diukur, substansial hingga mudah diakses.

Semakin baik strategi targeting yang diterapkan maka akan meningkatkan keputusan pembelian konsumen. Strategi targeting dapat dilakukan dengan meningkatkan pemilahan kapasitas pasar sasaran secara tepat dan memilih sasaran yang sesuai dengan target perusahaan agar konsumen tertarik untuk melakukan keputusan pembelian dengan tetap memperhatikan proses seleksi target pasar yang sesuai prosedur dari identifikasi pasar secara keseluruhan, mengimplementasikan marketing mix yang paling tepat hingga evaluasi dan kontrol terhadap operasional program pemasaran.

Semakin baik strategi positioning yang diterapkan maka seharusnya akan meningkatkan keputusan pembelian konsumen. Strategi positioning dapat dilakukan dengan meningkatkan kualitas produk atau jasa pelayanan yang lebih unggul daripada pesaing agar konsumen tetap loyal dalam melakukan pembelian dan dapat menjangkau pasar yang lebih luas, dengan tetap memperhatikan pedoman positioning antara lain mengutamakan segi kreativitas, simplicity hingga menggunakan 'bahasa' target audience secara tepat.

Rekomendasi penelitian selanjutnya hendaknya peneliti dapat menambah variabel yang diteliti, memperluas sampel penelitian, serta mencari petunjuk seperti buku dan jurnal yang lebih variatif gunamelengkapidan mendukung hasil penelitian agar lebih baik. Diharapkan peneliti selanjutnya dapat mengembangkan penelitian ini, dengan memasukkan pengaruh dari variabel di luar yang ada dalam penelitian ini sebagai bahan penelitian lanjutan.

\section{DAFTAR PUSTAKA}

Ariska, T. 2018. Pengaruh Implementasi Strategi Segmenting, Targeting dan Positioning Pada Warung Mie Endes Terhadap Keputusan Pembelian. Hal. 116. Artikel Skripsi Universitas Nusantara PGRI Kediri 14.1.02.02.0276 EkonomiManajemen

http://simki.unpkediri.ac.id/mahasiswa/file_ar tikel/2018/14.1.02.02.0276.pdf.

Hassan, A. 2013. Marketing dan KasusKasus Pilihan. Cetakan Pertama. Yogyakarta: CAPS.

Ismail, M. 2013. Strategi Pemasaran Untuk Membangun Citra Dan Merek Loyalitas. Bogor: IPB Press.

Kotler, P. \& Keller, K.L. 2009. Alih Bahasa: Benyamin Molan. Manajemen Pemasaran. Jakarta: PT. Indeks.

Mariyadi, A.O \& Arianta, S.B. 2015. PengaruhMakanan Cepat Saji Terhadap Daya Tarik Makanan Khas Daerah. (Online), tersedia: http://pateron.blogspot.co.id/2016/0 4/pengaruh-makanan-cepatsaji.html?m=1Ghozali, Imam. 2005. Aplikasi Analisis Multivariate dengan SPSS. Semarang: Badan Penerbit UNDIP

Oktavianti, R., Widiana, M.E. \& Noviandari, I. Pengaruh Diferensiasi, Positioning Dan Ekuitas Merek Terhadap 
Keputusan Pembelian Pada PT Smart Tbk Surabaya. Jurnal Mahasiswa, (Online), tersedia: fe.ubhara.ac.id.Manoor, Q. A. 2020 "1

Prasetyo D, Bambang. 2018. Komunikasi Pemasaran Terpadu. Malang: UB Press.

Priansa, D.J. 2017. Perilaku Konsumen dalam Persaingan Bisnis Kontemporer. Bandung: Alfabeta.

Ravindra, S. 2017. Analisis Pengaruh Strategi Segmenting,Targeting dan Positioning Terhadap Keputusan Pelanggan Membeli $\mathrm{Nu}$ Green Tea. Jurnal Ekonomika dan Manajemen. Vol. 6 No. 1 April 2017 ISSN: 2252-6226. Hal. 28-43. http://fe.budiluhur.ac.id/wpcontent/uploads/2017/08/c.ravindra.pdf.

Safitra, R.H. 2011. Analisis Pengaruh Strategi Segmenting, Targeting, Dan Positioning Terhadap Kepuasan Pelanggan Membeli Nu Green Tea., (Online), tersedia: fe.budiluhur.ac.id.

Sugiyono. 2015. Metode Penelitian : Pendekatan Kuantitatif, Kualitatif, dan R \& D. Bandung: Alfabeta.

Tjiptono, F, G. Chandra. 2012. Pemasaran Strategik. Yogyakarta: Andi. 